\title{
GRAMMATICAL PARALLELISM EFFECT IN ANAPHORA RESOLUTION: USING DATA FROM RUSSIAN TO CHOOSE BETWEEN THEORETICAL APPROACHES
}

\author{
Veronika Prokopenya, Laboratory for cognitive studies, Saint Petersburg State University, \\ St. Petersburg, Russia \\ E-mail: v.prokopenya@spbu.ru \\ Dr. Tatiana Chernigovskaya, Laboratory for cognitive studies, Saint Petersburg State University, \\ St. Petersburg, Russia \\ E-mail: t.chernigovskaya@spbu.ru
}

\section{A R T I C LE IN F O}

Original Research

Received: February, 22.2017.

Revised: March, 13.2017.

Accepted: March, 20.2017

doi:10.5937/IJCRSEE1701085P

UDK

811.161.1’367.626

$811.161 .1 ’ 367.2$

\section{Keywords: \\ reference, \\ coherence, \\ pronouns in Russian, information structure, grammatical roles.}

\begin{abstract}
A B S T R A C T
In the present study we explored structural parallelism, the preference of hearers to connect an unaccented pronoun to a referent occupying the same syntactic position. The traditional linguistic approach is based on the fact that referential preferences are associated with specific linguistic properties of potential antecedents of pronouns. Discourse-coherent approach is based on a hearer's coherence-driven expectations about discourse continuation and supposes a structural parallelism effect to be a by-product of establishing relations, which provide the coherence of discourse. From this point of view, parallel reading is caused by information structure. In order to investigate the role of grammatical and information structures in the parallelism effect, and to choose between the theoretical approaches, we addressed a flexible word-order language, which has several ways of focusing, such as Russian. The two experiments demonstrated that the use of non-contrastive focusing strategy reveals parallelism bias to be equally strong for both subject-subject and object-object dependencies. We found that syntactic roles' congruence is insufficient for the parallelism effect. Instead, parallel elements are required to occupy the topical position in the information structure of their clauses to provide the parallel reading. This evidence showed that structural parallelism effect is driven by information structure and is a by-product of establishing more general discourse relations, which provide its coherence.
\end{abstract}

(C) 2017 IJCRSEE. All rights reserved.

\section{INTRODUCTION}

Anaphora is one of the crucial factors that provide the coherence of discourse. Pronouns are explicit markers of the relations between the current utterance and the previously established context. The resolution of anaphora depends on a number of factors on different levels of language. While the algorithms

\footnotetext{
Corresponding Author

Veronika Prokopenya, Laboratory for cognitive studies, Saint Petersburg State University, St. Petersburg, Russia, E-mail: v.prokopenya@spbu.ru

cc)

This work is licensed under a Creative Commons Attribution - NonCommercial - NoDerivs 4.0. The article is published with Open Access at www.ijcrsee.com
}

of syntactic modules rule out certain antecedents (Reinhart, 2000; Reuland, 2003; Reuland 2011), the co-reference in discourse suggests that the antecedent could be freely chosen. Generally, pronouns tend to refer to the entities that are more accessible at a particular point of the discourse. This accessibility is provided by various factors related to the three components of the discourse structure: linguistic, intentional, and the focus of attention, or attentional structure. Linguistic structure groups units into discourse segments; the intentional structure determines the discourse segment's purposes and relations between them; finally, the attentional structure subserves the changes of attention within the discourse segments.

There are two approaches to determine mechanisms of anaphora resolution. According to the first, the interpretation of anaphoric 
dependences is guided by bottom-up information processing - from grammatical structure to the discourse. The main argument in favor of this approach is a large amount of experimental data demonstrating that referential preferences of the addressee are formed according to the grammatical characteristics of the referential expression and its antecedent. Thus, one of the main factors that influence reference assignment is the syntactic position of the antecedent. Referents in the subject position are more accessible than referents in the object or any other syntactic position, and consequently the subjects are the best antecedent candidates for pronouns (see Garnham, 2001 for overview). Another approach claims semantics and world knowledge to be central factors that determine reference assignment (Hobbs, 1979). Developing Hobbs` ideas about discourse coherence and the Expectation Hypothesis by J. Arnold (2001) A. Kehler et al. (2008) suggested that interpretative mechanisms of anaphora are based both on the expectations of the addressee about the discourse continuation (top-down mechanisms) and on the analysis of the concrete linguistic data (bottom-up mechanisms).

In order to choose between two theoretical approaches we addressed the phenomenon called structural parallelism, i.e. the preference of hearers to connect an unaccented pronoun in subject position to the previous subject NP (1-a), and an unaccented pronoun in object position to the previous object NP (1b).

(1) First Mary hugged Jane, and then... a. ... she hugged John. (she = Mary)

b. ...John hugged her. (her = Jane)

Parallelism is an interesting topic: there are several experimental studies on English data that demonstrated the parallelism bias to be a very strong perceptual strategy in pronoun resolution for both subject-subject and object-object dependencies (see Chambers and Smyth, 1998; Smyth, 1994; and Stevenson et al., 1995, inter alia). Below, we review the investigations of structural parallelism and provide evidence from two experiments on Russian data which show that the grammatical role parallelism is, in fact, a by-product of establishing more general discourse relations that provide its coherence.

\subsection{Structural parallelism}

The structural parallelism, or the parallel syntactic function phenomenon, refers to the preference of connecting a pronoun in subject position to an antecedent in subject position and a pronoun in object position to an antecedent in object position (Sheldon, 1974). Thus, in (2) the pronoun 'he' in the second sentence preferably refers to 'Peter', and the pronoun 'him' - to 'John'. yard.

(2) Peter saw John in the University

He asked him how the examination was. (he = Peter; him $=$ John)

The first experimental studies of structural parallelism found a strong preference for pronouns to refer to the antecedents in the same syntactic position (Grober et al., 1978). However, these studies showed no distinguished preference for parallel syntactic position from subject preference (or subjecthood), since only the subject pronouns were investigated. Later studies demonstrated a parallelism effect for both subject-subject and objectobject dependencies (Chambers and Smyth, 1998; Smyth, 1994). Smyth (1994) formulated the parallelism rule in his Extended Feature Match Hypothesis, which predicts an ambiguous pronoun with two or more grammatically and pragmatically possible antecedents to be 'interpreted as co-referential with the candidate that has the same grammatical role' (p. 197). At the same time, it turned out that the bias is strong only if the constituents have the same structure and congruent thematic roles. If these conditions don 't hold, the parallelism effect decreases (3).

(3) Kathy tried to catch Joy and Michael bored her. (her $=$ ?)

(Chambers and Smyth, 1998)

Another experimental study reports that if utterances are not structurally congruent, the subject and non-subject pronouns are both likely to be connected to the subject antecedents (Stevenson et al., 1995). As a result, the definition of parallelism was supplemented by a requirement of the congruence of constituents' structure within parallel utterances.

Notwithstanding the parallelism preference is a very strong bias, it can be easily overridden by pragmatic factors.

(4) John hit Bill, and then Mrs. Smith punished him. (him = John)

(Zuckerman et al., 2002)

The parallel function strategy assumes that in (4) the pronoun 'him' should refer to the NP 'Bill', i.e. object-object dependency. However, it is obvious that in the described situation the person who was hitting is most likely to be punished; in other words, 'him' (pronoun in object position) will refer to 'John' (NP in subject position). 
Finally, the parallelism affects only unaccented pronouns. When a pronoun receives a phrasal stress, the shift in reference occurs (Akmajian and Jackendoff, 1970). The definition of this referential shift was formulated in the stress rule prescribing that in order to correctly interpret an accented ambiguous pronoun one needs to establish the reference according to the parallelism (under the unstressed reading), and then cancel it and select another available referent as an antecedent for the pronoun (see Baauw et al., 2011; Kameyama, 1999, inter alia). Thus, in (5-a) the preferable antecedent for the accented pronoun 'SHE' will be 'Jane', and in (5-b) the preferable antecedent for pronoun 'HER' will be 'Mary' (stress is marked by capital letters).

(5) First Mary hugged Jane, and then... a. ...SHE hugged John. (SHE = Jane) b. ...John hugged HER. (HER = Mary)

Summarizing, the traditional linguistic view on parallelism is based on the fact that referential preferences are associated with specific linguistic properties of potential antecedents of pronouns. From this perspective the interpretation of pronouns in sentences with structural parallelism involves several operations. The first step is the recognition of parallel structures, checking their congruence and the interpretation of lexical semantics and pragmatics of predicates. If there are no pragmatic preferences (such as in (4) above), the parallel interpretation construal can be constructed, i.e. pronoun is to be identified with an NP in the same syntactic position (step 2). In the case of the accentuation of a pronoun, step 3 is added, called referential shift, where the antecedent selected by parallelism is rejected and an alternative candidate is chosen (Avrutin et al., 1999; Baauw et al., 2011). Note that the stress rule does not determine the preferable antecedent for a pronoun; it only gives a signal that the referent selected by parallelism must be rejected. If there are only two potential antecedents, like in (5), the preferable candidate will be chosen automatically. If there are several candidates, like in (6), the stress only rules out the NP 'Bill' but leaves the pronoun ambiguous between 'John' and 'Peter'.

(6) John introduced Bill to Peter, and then Mary introduced HIM to Frank. (him $\neq$ Bill; him =?)

(Baauw et al., 2011)

\subsection{Coherence-driven approach to parallelism}

Kehler et al. (2008) proposed another approach to pronoun interpretation. Developing the idea by Hobbs (1979), they claim that the identification of a correct referent for the pronoun is a by-product of establishing more general discourse relations (Explanation, Parallel, Result, etc.) to provide the coherence of the discourse. In the context of the structural parallelism, Kehler $(2002,2005)$ argues that this effect is affiliated with Resemblance coherence relations, such as Parallel, which 'are established by identifying a 'common topic' for a set of utterances' (Kehler, 2005, p. 108). This 'common topic' represents a kind of background, i.e. some given information, which is opposed to the focal entities, i.e. the new information. An entity can be counted as a part of the background only if it is co-referent with its parallel element. Therefore, parallelism is driven by information structure, and in fact, is a by-product of information structure establishing. In (1-a), repeated in (7-a) 'Mary' becomes part of the background (e.g. Whom has Mary hugged), and 'John' is a focal element, opposite to 'Jane' in this Parallel relation. Similarly, 'Jane' is a part of the background in (1-b), repeated in (7-b), and 'John' is focal element, opposed this time to 'Mary' (e.d. Who has hugged Jane).

(7) \{First Mary hugged Jane, and then\}

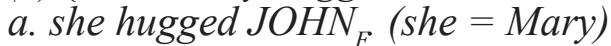

b. JOHN . hugged her. (her = Jane)

Kehler's model is based on the hearer's coherence-driven expectations about the discourse continuation and correlates with Arnold's Expectancy Hypothesis, which supposed the referents accessibility to be based on the hearer's probabilistic expectations about which of the referents will be mentioned next in the discourse (Arnold, 2001). It stands to reason that Parallel relations are expected by hearers. Corpus studies, which obviously reflect speech production process, demonstrated that similar structures tend to appear near each other with a probability above chance level. The robust effect of parallelism was shown for a variety of NP types. It occurs in different contexts, i.e. between NPs in the same sentence and NPs in two adjacent sentences (Dubey et al., 2008). This probability underlies the hearer's expectations about how the discourse is likely to be continued.

As is seen from above, the Parallel reading is provided by information structure. Speakers use basic tools of focusing, such as 
intonation, for example, to manage hearer's expectations during the discourse comprehension. In cases of typical Resemblance relations (Parallel), the given entities form the background that is introduced in topical unstressed position, while the new entities, which are introduced in contrast to each other (like 'John' and 'Mary' in the example (7-a) above), must be focused (in English, by accentuation of the focal entity). However, in some cases the given NP and the given verb form a contextual new VP. This new VP represents new information, which doesn 't correlate with the hearer's expectations, and consequently, for the purpose of attracting hearer's attention to this new information, the corresponding entity must be focused by any available tool, including the contrastive stress. Thus, in (5), repeated in (8), pronouns should be focused to provide the Parallel reading, where 'Mary' and 'Jane' do the same act to someone in (8a), and where somebody does the same act to both 'Mary' and 'Jane' in (8-b).

(8) \{First Mary hugged Jane, and then\} a. $S H E$, hugged JOHN $F(S H E=$ Jane $)$

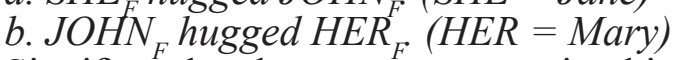

Significantly, the stress pattern in this case is independent of the referential choice, i.e. of the choice to pronominalize the subject in $(8-a)$ and the object in $(8-b)$ or to use the full NPs, and it concerns the co-reference in general rather than pronominalization.

In relation to the structures such as (4) above, repeated in (9), the described coreferential principles don't apply, since such sentences represent another type of coherence relation - the Cause-Effect relations (e.g. Result), not Resemblance (e.g. Parallel). With this reading, the coordinate conjunction 'and then' can be paraphrased as 'and as a result', whereas the conjunction in Parallel construal means 'and similarly'. The Result construal is based not on the similarity and contrast, but instead on the world knowledge about what effect can be caused by some act; and the information structure is defined in accordance with this knowledge (see Kehler, 2005 for details).

(9) John hit Bill, and then Mrs. Smith punished him. (him = John)

Taking all things together, the main idea of a coherence-driven approach to the pronoun resolution is that the parallelism effect represents an epiphenomenon of establishing the Resemblance relations, which are one of the means to provide the coherence of discourse.

In order to investigate the role of information structure in the parallelism effect, we addressed a flexible word-order language, which has several ways of focusing (e.g. by word-order permutation or by accentuation), such as Russian.

\subsection{The information structure in Russian}

Russian is a flexible word-order language, i.e. it permits changing the order of sentence constituents without any change in grammatical relations between them. Different word orders reflect the information structure encoding, dividing the sentence into given (topic) and new (focus) information. The way of establishing the information structural roles (topic and focus) depends on the two types of parameters: syntactic, i.e. default word-order and its variability; and prosodic, i.e. the default position of main phrasal stress and its capacity to be shifted (Cinque, 1993). The canonical word-order (that is appropriate for zero context) in Russian is SVO (subjectverb-object), with a high degree of flexibility. The main phrasal stress is located on the rightmost constituent (final stress prominence) by default, but can be easily moved in a relevant context. Therefore, two strategies of focusing are available in Russian: (i) by shifting the phrasal stress, i.e. by accentuation of the entity that should be focused (10-a); (ii) by permutation of the canonical word-order (SVO), so that the focal entity occupies the rightmost position, i.e. position of the main phrasal stress (10-b). The first strategy is mostly used for contrastive focusing, the second one - for non-contrastive focusing.

(10) Kto ispek pirog?

Who-Nom baked the pie-Acc?

a. [Moya MAMA] $]_{F}$ ispekla pirog.

[My MOTHER-Nom] $]_{F}$ baked the pie-Acc.

b. Pirog ispekla [moya MAMA]

The pie-Acc baked [my MOTHER-Nom]

By comparison, in fixed word-order languages, such as English, only the first strategy is available (11), and the stress is considered as a main tool of information structure establishing.

(11) Who baked the pie?

[My MOTHER] baked the pie.

We investigated the parallelism effect in Russian: the influence of the information structure on the pronominal reference and the role of word-order in pronoun resolution. Experiment 1 deals with the parallelism effect in the fully congruent adjacent clauses, with canonical SVO word-order and un-stressed pronouns in either subject or object position 
in the second clause. We also evaluated the role of contrastive stress in referential shift (in parallelism violation). Experiment 2 examines the role of word-order permutations in pronoun resolution, particularly, predicting that the parallelism effect decreases when the two clauses are not fully congruent.

\section{EXPERIMENT 1}

\subsection{Materials and methods}

The first experiment addresses the parallelism effect in Russian and the influence of the stress on referential shift.

In a 2 x 2 design, stimulus sets were constructed with four variants $(12 \mathrm{a}-\mathrm{d})$, each composed of two clauses. The first clause was an introduction of two possible referents of the same gender, the second clause contained an ambiguous pronoun. Both clauses contained the same transitive verb in the active voice. Only the canonical SVO word-order was used.

(12) Snačala ženšin-a pošekotala devočk-u, a potom...

First the woman-Nom tickled the girlAcc, and then...

a. ... ona pošekotala malčik-a. [Parallelism; Unstressed Subject Pronoun]

...she-Nom tickled the boy-Acc.

b. ... malčik pošekotal ee. [Parallelism;

Unstressed Object Pronoun]

... the boy-Nom tickled her-Acc.

c. ... ONA pošekotala malčik-a. [Stress;

Stressed Subject Pronoun]

... SHE tickled the boy-Acc.

d. ... malčik pošekotal EE. [Stress; Stressed Object Pronoun]

... the boy tickled HER-Acc.

Thirteen stimulus sets were constructed for a total of fifty-two experimental stimuli. Each set varied pronoun position (subject/ object) and pronoun accent (un-stressed pronoun/stressed pronoun). In addition to the stimuli items, fifty-two filler passages of the same length were created. All the fillers were unambiguous sentences. Thirteen of them contained reflexives, twenty-six contained unambiguous third-person singular pronouns, and thirteen fillers contained unambiguous third-person plural pronouns.

As we aimed to investigate the effect of structural parallelism on ambiguous pronoun resolution, we needed to avoid the influence of world knowledge on the reference. To create the contexts in which either referent was a plausible antecedent for the pronoun, we introduced four characters which were men- tioned in the materials (in both, stimuli and fillers). Those were 'the man', 'the woman', 'the boy', and 'the girl'. Our participants were instructed that all the stories describe a kind of a game between these characters, who perform different acts.

Picture selection task was chosen as a method. For each experimental item a set of four pictures was presented on two pages of A4 size paper. One picture on the left page depicted the first clause, and three pictures were on the right page. Two of them belonged to the second part of the sentence, representing two possible interpretations of ambiguous pronouns (with two possible referents). The third picture on the right page was a filler distracter, on which the same referents perform another action.

All the 104 items were presented orally at random and repeated as often as necessary. The participants were asked to listen to the sentences, while looking at the pictures, and then to point at the picture that corresponds to the sentence. Each participant was tested separately in a quiet room. The entire experimental procedure lasted approximately $30 \mathrm{~min}$.

Twenty-six healthy adults, naïve to linguistic theory, participated in the experiment on voluntary basis. All were self-reported monolingual native speakers of Russian. Participants were informed about the experiment procedure, the possibility of quitting experiment at any time, and about the fact that all the collected data would remain anonymous. After that they signed a written informed consent.

\subsection{Results}

The $2 \times 2$ analyses of variance (ANOVA) with the factors pronoun position (subject/object) and pronoun accentuation (unstressed/stressed) were performed for subjects (F1) and items (F2). The dependent measure was the proportion of judgments indicating referents in accordance with the parallelism. By this criterion, the significant difference between stressed and unstressed conditions demonstrates the presence of stress rule, i.e. the influence of a pronoun accentuation on shift in reference. Mean proportion of responses given in favor of parallelism in all four conditions is shown in Table 1.

We got an important effect of the stress on pronoun resolution $(\mathrm{F} 1(1,25)=88.355, \mathrm{p}<$ $0.001 ; \mathrm{F} 2(1,12)=186.520, \mathrm{p}<0.001)$. There was also an effect of pronoun syntactic posi- 
tion $(\mathrm{F} 1(1,25)=48.204, \mathrm{p}=0.001 ; \mathrm{F} 2(1,12)=$ 96.429, $\mathrm{p}<0.001)$.

Table 1. Mean proportion of responses identifying the referent in similar syntactic position as the antecedent of pronoun (according to parallelism rule)

\begin{tabular}{ccc}
\hline & \multicolumn{2}{c}{ Pronoun accentuation } \\
\cline { 2 - 3 } $\begin{array}{c}\text { Pronoun syntactic } \\
\text { position }\end{array}$ & Unstressed & Stressed \\
\hline Subject & 0.970 & 0.651 \\
Object & 0.775 & 0.269 \\
\hline
\end{tabular}

The comparisons revealed a greater effect of parallelism for subject-subject dependencies than for object-object dependencies $-97 \%$ vs $78 \%$. The significant interaction between pronoun position and pronoun accentuation was shown $(\mathrm{F} 1(1,25)=8.667$, $\mathrm{p}$ $=0.007 ; \mathrm{F} 2(1,12)=25.497, \mathrm{p}<0.001)$. The rules - parallelism and stress rule - have not shown the equally strong effect for both subject and object pronouns. Thus, the effect of stress turned out to be significantly smaller than the parallelism effect in the sentences with subject pronouns $(\mathrm{F} 1(1,25)=109.680$, $\mathrm{p}<0.001 ; \mathrm{F} 2(1,12)=288.235, \mathrm{p}<0.001)$, whereas no reliable difference was found between the effects in the sentences with object pronouns $(\mathrm{F}$ 's $<1)$. The overall accuracy of the responses on the filler items containing unambiguous pronouns was $100 \%$.

\subsection{Discussion}

Experiment 1 demonstrated that parallelism of syntactic position affects ambiguous pronoun resolution in Russian. A strong bias towards interpreting the unstressed subject pronoun to refer to the NP in subject position, and the unstressed object pronoun to refer to the NP in object position was found. However, the effect degree is significantly different between subject-subject and object-object dependencies: while subject pronouns (12-a) were across-the-board connected to antecedents in subject position (97\%), object pronouns (12-b) referred to their parallel entities only in $78 \%$ of cases. The main effect of the contrastive stress was demonstrated; however, the results for subject and object pronouns seem to be contradictory. We found that the robust stress effect in object-object dependencies (12-d) resulted from referring the stressed object pronouns to the subject NPs. At the same time, this effect dramatically decreases in sentences with stressed subject pronouns (12-c), where only $35 \%$ of responses followed the stress rule. It is obvious that the stress is not completely ignored (such being the case we would have no intended responses) but for some reason our participants tended to interpret the stressed subject pronouns by analogy with unstressed ones. Combining these results with scores on un-stressed object pronouns (12-b), which in $22 \%$ of responses were connected to the subject NPs, we get evidence in support of Centering and some other theories that consider subjects to be preferable antecedent candidates for ambiguous pronouns (Ariel, 2001; Grosz et al., 1995). Moreover, the subject preference (subjecthood) is considered as a default strategy in pronoun resolution (Zuckerman et al., 2002-a, inter alia). Following this approach in relation to our data we may expect higher scores on all conditions where subject NPs are intended to be pronoun antecedents over the conditions where object NPs are intended antecedents. In fact, Experiment 1 demonstrated the strongest effect of parallelism in (12-a) in comparison with (12b) and the strongest effect of contrastive stress in (12-d) in comparison with (12-c). However, the overage of the intended responses in (12a) over (12-b), which both supposed subjects to be pronoun antecedents $(97 \%$ vs $73 \%$, see Table 1), remains unexplained. Another unanswered question is why the parallelism effect turned to be stronger than the stress effect.

We propose an interpretation for these results based on coherence-driven approach. Let us assume that the parallelism and the stress rule are by-products of the information structure establishing. As was stated above, the two strategies of focusing are available in Russian - by moving the focal entity to the rightmost position, which receives the phrasal stress by default, or by shifting the phrasal stress on the word that should be focused. The former strategy is typical for non-contrastive focusing; the latter is used mainly for contrastive focusing in an appropriate context. As only sentences with canonical SVO wordorder were included in the experiment, we had to use both strategies. Thus, in the parallel sentences with subject pronoun the focal word occupies the final position in the clause and receives the main phrasal stress (12-a), whereas in parallel sentences with object pronoun the main phrasal stress is shifted to the word that should be emphasized (12-b). The same is relevant for stressed conditions, where the main focusing strategy is applied in sentences with 
object pronouns (12-d), while the contrastive focusing is used in sentences with subject pronouns (12-c). If pronoun interpretation is associated with information structure constraints, then it must be sensitive to the choice of focusing strategy. The application of contrastive focusing in zero contexts may cause the decrease of the main effects (e.g. parallelism). Generally, it is reflected in the fact that the main effects are stronger in conditions with default focusing strategy - (12-a) and (12-d), then in conditions (12-b) and (12-c), where the contrastive focusing is used. Thus, we got significantly fewer of intended answers in (12-c) in contrast to (12-d) than in (12-b) in contrast to (12-a), see Table 1.

However, the reduction ration is not the same in both condition pairs: the stress effect decreases more than parallel effect. We suppose that these results were caused by the interaction of the focus establishing and the choice of anaphoric expression, which took place in (12-c). In Russian, typical markers of contrastive focus are demonstrative pronouns, such as 'tot' (that-Masc.) and 'ta' (that-Fem.). The use of personal pronouns in the position of contrastive beginning is possible but not desirable. In accordance with the model proposed by Rohde and Kehler (2014), the interpretation of pronouns depends on a hearer's expectation of which referent will be subsequently mentioned in the discourse and her expectation that a personal pronoun will be used as an anaphoric expression. Expectations about next-mentioned referents are provided by semantics, world knowledge and information structure assignment. The influence of the first two components was counter-balanced in our experiment. As to the information structure, the choice of contrastive focusing strategy without appropriate context misleads the hearer's expectation. On the other hand, the probability that the pronoun in focus will refer to the intended NP (to 'devočka' (the girl) in (12-c) is low, as the demonstrative 'ta' (that) is more expected in this role (the hypothesis that the use of pronouns and demonstratives is dichotomous for parallel and unparallel reading will be tested in Experiment 2). Taking together the undetermined next-mention expectations and low-level probability of personal pronoun use, we receive low preference for connection of the subject pronoun with the object NP in (12-c).

We argue that the use of non-contrastive focusing strategy and the adequate choice of anaphoric expressions will reveal equal parallelism bias for both subject-subject and object- object dependencies. We also claim that parallel elements should be identified as topics in their clauses, otherwise the parallelism effect is reduced. These predictions are examined in Experiment 2.

\section{EXPERIMENT 2}

\subsection{Materials and methods}

In the second experiment we investigated the role of information structure in the parallelism bias, which provides the division on topic and focus, given and new information. As was stated above, the parallelism bias could be successfully applied only if the common background (common topic) for both clauses can be identified. We examined the interpretation of pronouns in sentences with parallelism of syntactic position during the silent reading, when the division on topic and focus (i.e. given and new information) is provided only by word-order and silent prosody. In reference to J. D. Fodor (2002), we supposed that the default prosodic contour, with the main phrasal stress on the last word of the clause, is projected onto the stimuli. From this perspective the referent mentioned first in sentences with parallelism (12) is considered as the topic of the preamble clause, and the referent mentioned second - as the focus. The same division is relevant for target clauses with a pronoun.

We found a robust parallelism effect for subject-subject dependencies in Experiment 1, so that the goal of Experiment 2 was to test whether personal pronouns and demonstratives in subject position are dichotomous for parallel and unparallel reading. We also examined the influence of the referent's position in information structure on subject-pronoun resolution. Since Experiment 1 demonstrated the lower parallelism effect for object-object dependencies than for subject-subject dependencies, the question arises what these results are caused by. Two possible explanations have been already discussed above. The first one is based on the linguistic properties of referents and claims that subject are always most preferable antecedent candidates for pronouns than non-subjects. Although parallelism seems to be a robust bias, the influence of subjec-thood affects it, making the effect stronger for subject pronouns and weaker for object pronouns. The second explanation addressees the means of focusing used in experimental sentences and assumes that the use of contrastive focusing strategy (i.e. focusing by shifting the 
phrasal stress) in parallel structures with object pronouns (12-b) causes the reduction ratio of answers in accordance with parallelism. We suppose that parallelism bias would be equally strong for both subject-subject and object-object dependencies if the same focusing strategy is applied. In Experiment 2 we manipulated the word-order in both parts of the stimuli sentences with object-pronouns to test this statement.

The materials were based on the stimuli of Experiment 1. Two stimulus sets were constructed. The first set (13) contained a pronoun in subject-position and varied the type of pronoun (personal/demonstrative) and the wordorder in the preamble clause (SVO/OVS). The second set (14) contained a pronoun in object position and varied word-order in the preamble clause, i.e. referents ' position (SVO/ OVS), and the word-order in the target clause, i.e. pronoun position (SVO/OVS).

(13) a. Snačala ženšin-a pošekotala devočk-u, a potom ona pošekotala malčik-a. (SVO-SVO)

First the woman-Nom tickled the girlAcc, and then she-Nom tickled the boy-Acc.

b. Snačala ženšin-a pošekotala devočk-u, a potom ta pošekotala malčik-a. (SVO-SVO, Dem.)

First the woman-Nom tickled the girlAcc, and then that-Nom,Fem tickled the boyAcc.

c. Snačala devočk-u pošekotala ženšin-a, a potom ona pošekotala malčik-a. (OVS-SVO)

First the girl-Acc tickled the womanNom, and then she-Nom tickled the boy-Acc.

(14) a. Snačala ženšin-a pošekotala devočk-u, a potom malčik pošekotal ee. (SVO$S V O)$

First the woman-Nom tickled the girlAcc, and then the boy-Nom tickled her-Acc.

b. Snačala ženšin-a pošekotala devočk-u, a potom ee malčik pošekotal. (SVO-OVS)

First the woman-Nom tickled the girlAcc, and then her-Acc tickled the boy-Nom.

c. Snačala devočk-u pošekotala ženšin-a, a potom malčik pošekotal ee. (OVS-SVO)

First the girl-Acc tickled the wom-anNom, and then the boy-Nom tickled her-Acc.

d. Snačala devočk-u pošekotala ženšin-a, a potom ee pošekotal malčik. (OVS-OVS)

First the girl-Acc tickled the womanNom, and then her-Acc tickled the boy-Nom.

Total material contained 91 stimuli items, which were combined with fillers from Experiment 1.

Participants were given a questionnaire, for which they read experimental sen- tences and answered a question immediately after, as in (15).

(15) Snačala ženšin-a pošekotala devočk-u, a potom ona pošekotala malčik-a.

Kto pošekotal malčik-a?

First the woman-Nom tickled the girlAcc, and then she-Nom tickled the boy-Acc.

Who tickled the boy?

The answers supposed to indicate the antecedent chosen by participants while interpreting the ambiguous pronoun.

Thirty healthy adults, naïve to linguistic theory, participated in the experiment. All were self-reported monolingual native speakers of Russian. No one in this group had participated in Experiment 1.

\subsection{Results}

We analyzed the interpretations of subject (13) and object (14) pronouns separately. The results for subject pronouns are presented in Table 2. The dependent measure for statistical analysis was the rate of assignments to subject antecedent.

Table 2. Mean proportion of responses identifying the referent in subject position as the antecedent of subject pronoun

\begin{tabular}{ccc}
\hline Word-order in & \multicolumn{2}{c}{ Pronoun type } \\
\cline { 2 - 3 } conjoint clauses & Personal & Demonstrative \\
\hline SVO-SVO & 0.895 & 0.097 \\
OVS-SVO & 0.677 & $\mathrm{xxx}$ \\
\hline
\end{tabular}

Greater effect of the anaphor type was found $(\mathrm{F} 1(1,29)=229.741, \mathrm{p}<0.001 ; \mathrm{F} 2(1,12)$ $=902.529, \mathrm{p}<0.001)$. Personal pronouns were connected with subject referents in $89.5 \%$ of responses, while this rate for demonstratives was only about $9.7 \%$. Our participants tended to refer the demonstratives to antecedents in object position. It was also shown that the referent position factor influenced pronoun resolution $(\mathrm{F} 1(1,29)=25.474, \mathrm{p}<0.001 ; \mathrm{F} 2(1,12)$ $=50.058, \mathrm{p}<0.001)$.

The results for object pronouns interpretation are presented in Table 3. 
Table 3. Mean proportion of responses identifying the referent in object position as the antecedent of object pronoun

\begin{tabular}{ccc}
\hline \multirow{2}{*}{$\begin{array}{c}\text { Object referent } \\
\text { position }\end{array}$} & \multicolumn{2}{c}{$\begin{array}{c}\text { Object pronoun } \\
\text { position }\end{array}$} \\
\cline { 2 - 3 } & OVS & SVO \\
\hline OVS & 0.852 & 0.667 \\
SVO & 0.814 & 0.528 \\
\hline
\end{tabular}

A mixed factorial analysis with repeated measures (RM ANOVA) was conducted with object referent position in information structure (Topic/Focus) and object pronoun position (Topic/Focus) as factors. The dependent measure was the rate of assignments to object antecedents. The analysis confirmed that both the referent position $(\mathrm{F} 1(1,29)=9.143$, $\mathrm{p}=0.005 ; \mathrm{F} 2(1,12)=19.561, \mathrm{p}=0.001)$ and the pronoun position $(\mathrm{F} 1(1,29)=29.541, \mathrm{p}<$ $0.001 ; \mathrm{F} 2(1,12)=138.217, \mathrm{p}<0.001)$ influence the parallel reading. However these two factors did not enter into any significant interaction $(\mathrm{F} 1(1,29)=2.459, \mathrm{p}=0.128 ; \mathrm{F} 2(1,12)$ $=5.929, \mathrm{p}=0.031)$. The comparison of the results for subject-subject and object-object dependencies in sentences with parallel elements at the beginning, i.e. (13-a) and (14-d), did not reveal any significance $(\mathrm{F}<1)$. The parallelism effect in these two conditions was equally strong. A binominal test demonstrates that the rate of object antecedent assignment for object pronoun in the condition with canonical SVO word-order in both clauses, such as (14-a), is not significantly different from chance $(\mathrm{p}=0.290)$.

\subsection{Discussion}

The results of Experiment 2 demonstrated that the parallelism bias equally holds for subject-subject and object-object dependencies. No evidence in favor of subject preference was found. However, the grammatical roles' congruence is insufficient for the parallelism effect. We got good results for (14-d) and chance level answers for (14-a) although grammatical and thematic roles of constituents are identical in these sentences. We propose an analysis based on a coherence-driven approach to the parallelism bias. As was said at the beginning of this paper, pronouns are explicit markers of discourse coherence. In other words, the use of a pronoun gives a signal to the hearer that the current utterance is related to the previous context and that some kind of coherence relation (e.g. Parallel, Result, Oc- casion, etc.) is established by the speaker and must be identified by the hearer or reader. The syntactic similarity of adjacent utterances does not guarantee the parallel reading per se. Different types of coherence relations may have the same grammatical structure (see Kehler et al., 2008 for discussion). To establish a particular type of relation, e.g. parallel, a speaker must compose an appropriate information structure, realizing background vs focus partition in a particular way. In the process of oral communication two instruments are available in Russian to provide this information structural partition - the word-order permutations and stress. In written communication only word-order remains. In the absence of a wide context (such as in our experimental conditions) the word-order might be insufficient for unambiguous information structural partition. Experiment 2 showed that the most favorable condition for parallel relation is created when entities, which form a background, occupy the first position in their clauses, the typical position for topic elements. Thus, readers don't have difficulty in identifying parallel elements in (13-a) and (14-d), and successfully corefer pronouns to their parallel referents. With regard to (13-b), the lexical marker 'ta' ('thatFem'), being stressed by default, definitely determines the contrastive reading (e.g. 'who did what to whom') which was shown in $90 \%$ of responses. In other conditions the personal pronoun (14-c), or its parallel element (13-c, 14-b), or both (14-a) occupied the final position in the clause, which is the default position of the phrasal stress, i.e. these elements are focused. No common background can be formed in these cases, and consequently, no parallel relations are established here.

The high scores for (14-b), repeated in (16) $-81 \%$ of responses in accordance to the parallelism - seem to be an exception, which deserves a fuller explanation.

(16) Snačala ženšin-a pošekotala devočk-u, a potom ee malčik pošekotal. (SVOOVS)

First the woman-Nom tickled the girlAcc, and then her-Acc tickled the boy-Nom

We suppose that a different word-order in adjacent clauses interferes with establishing a parallel relation. Another kind of relations available for (16) is the occasion relation, which supposes 'a connect sequence of events that center around a common system of entities' (Kehler, 2005, p. 110). This means that some event ('the boy tickled somebody') happened after another event ('the woman tickled the girl'). The object of the second action is 
mentioned by personal pronoun and occupies the position of topic (at the beginning of the clause). According to the linear thematic progression, the focus of the previous clause is expected to become the topic of the next one (Danes, 1974). As such, the pronoun refers to the focal element of the first clause, that is, to the object referent 'devočk-u' ('the girl'). Thus, the coincidence of the syntactic roles of the pronoun and its antecedent is a by-product effect in this case.

\section{CONCLUSIONS}

In the present study we explored anaphora resolution in Russian and structural parallelism. The traditional linguistic view on parallelism is based on the fact that referential preferences are associated with specific linguistic properties of potential antecedents of pronouns. Pronoun accentuation plays a significant role in this approach. Thus, if an ambiguous pronoun receives a stress, then the parallelism is expected to be violated and the shift in reference takes place. On the other side, discourse-coherent approach supposes a structural parallelism effect to be a by-product of establishing the Resemblance relation, which is one of the means to provide the coherence of discourse. This approach is based on a hearer's coherence-driven expectations about discourse continuation and supposes referent accessibility to be based on probability of referents mentioned next in the discourse. From this point of view, parallel reading is caused by information structure. In order to investigate the role of the information structure in the parallelism effect, and to choose between the two approaches, we conducted two experiments on Russian. Being flexible word-order language with a rich morphology, Russian gives us an opportunity to investigate separately the influence of different factors on reference assignment and complete analysis made on the basis of English data (Prokopenya et al., 2014; Prokopenya, 2014).

Experiment 1 examined the parallelism effect in Russian and evaluated the role of contrastive stress in a referential shift. The results showed that parallelism generally holds for both subject-subject and object-object dependencies. The effect of contrastive stress was significantly smaller. The results varied between the conditions. The explanation based on linguistic properties of the referents supposes that an additional factor, such as subject preference, interferes with the parallelism bias. However, this approach fails explain the evidence from Russian, e.g. why the stress effect was significantly smaller than that of parallelism. In reference to the coherence-driven approach, stress is not an independent factor that influences reference assignment, but it is considered as one of the means participating in information structure establishing, i.e. in topic/focus partition and with word-order permutations. Furthermore, if a pronoun interpretation is associated with information structure constraints, then it must be sensitive to the choice of a focusing strategy. The use of it (focusing by stress shifting) without an appropriate context misleads a hearer's expectation about the discourse continuation and prevents parallelism bias from being applied. Experiment 2 demonstrated that the use of non-contrastive focusing strategy reveals parallelism bias to be equally strong for both subject-subject and object-object dependencies. Moreover, we found that syntactic roles' congruence is insufficient for the parallelism effect. Instead, parallel elements are required to occupy the topical position in the information structure of their clauses to provide the parallel reading.

Summarizing, the evidence from a flexible word-order language, such as Russian, shows that structural parallelism effect is driven by information structure and, in fact, is an epiphenomenon of establishing more general discourse relations, which provide its coherence.

\section{ACKNOWLEDGEMENTS}

The study was supported by grant \#1418-02135 from the Russian Science Foundation.

\section{Conflict of interests}

Authors declare no conflict of interest.

\section{REFERENCES}

Akmajian, A., and Jackendoff, R. (1970). Corefentiality and stress. Linguistic Inquiry 1, 124-126.

Ariel, M. (2001). Accessibility theory: An overview. Text representation: Linguistic and psycholinguistic aspects, 8, 29-87.

Arnold, J. E. (2001). The effect of thematic roles on pronoun use and frequency of reference continuation. Discourse Processes, 31(2), 137-162. http:// dx.doi.org/10.1207/S15326950DP3102_02

Avrutin, S., Lubarsky, S., \& Greene, J. (1999). Comprehension of contrastive stress by Broca's aphasics. Brain and Language, 70(2), 163-186. http://dx.doi.org/10.1006/brln.1999.2154 
Baauw, S., Ruigendijk, E., Cuetos, F., \& Avrutin, S. (2011). The interpretation of stressed and nonstressed pronouns in Spanish language breakdown. Aphasiology, 25(3), 386-408. http:// dx.doi.org/10.1080/02687038.2010.493295

Chambers, C. G., \& Smyth, R. (1998). Structural parallelism and discourse coherence: A test of centering theory. Journal of Memory and Language, 39(4), 593-608. http://dx.doi.org/10.1006/ jmla.1998.2575

Cinque, G. (1993). A null theory of phrase and compound stress. Linguistic inquiry, 24(2), 239-297.

Danes, F. (Ed.). (1974). Papers on functional sentence perspective (Vol. 147). Walter de Gruyter GmbH \& $\mathrm{Co} \mathrm{KG}$

Dubey, A., Keller, F., \& Sturt, P. (2008). A probabilistic corpusbased model of syntactic parallelism. Cognition, 109(3), 326-344. doi:10.1016/j.cognition.2008.09.006

Fodor, J. D. (2002). Prosodic disambiguation in silent reading. In PROCEEDINGS-NELS (Vol. 1, No. 32; VOL 1, pp. 113-132).

Garnham, A. (2001). Mental models and the interpretation of anaphora. Psychology Press.

Grober, E. H., Beardsley, W., \& Caramazza, A. (1978). Parallel function strategy in pronoun assignment. Cognition, 6(2), 117-133. http://dx.doi. org/10.1016/0010-0277(78)90018-5

Grosz, B. J., Weinstein, S., \& Joshi, A. K. (1995). Centering: A framework for modeling the local coherence of discourse. Computational linguistics, 21(2), 203-225.

Hobbs, J. R. (1979). Coherence and coreference. Cognitive science, 3(1), 67-90.

Kameyama, M. (1999). Stressed and unstressed pronouns: complimentary preferences. In Focus: Linguistic, Cognitive, and Computational Perspectives, eds. P. Bosch, and R. van der Sandt (Cambridge: Cambridge University Press) 306-321.

Kehler, A. (2002). Coherence, reference, and the theory of grammar. Stanford, CA: CSLI publications.

Kehler, A. (2005). Coherence-driven constraints on the placement of accent. In Proceedings of the 15th Conference on Semantics and Linguistic Theory (SALT-15), eds. E. Georgala, and J. Howell (Cornell University: CLC Publications). 98-115.

Kehler, A., Kertz, L., Rohde, H., \& Elman, J. L. (2008). Coherence and coreference revisited. Journal of semantics, 25(1), 1-44. https://doi.org/10.1093/ jos/ffm018

Poesio, M., Stevenson, R., Di Eugenio, B., \& Hitzeman, J. (2004). Centering: A parametric theory and its instantiations. Computational linguistics, 30(3), 309-363. doi:10.1162/0891201041850911

Prokopenya, V. (2014). Language breakdown as a result of limited processing resources. Activitas $\mathrm{Ner}$ vosa Superior Rediviva, 56(1-2), 50.

Prokopenya, V., Chernigovskaya, T., and Khrakovskaya, M. (2014). Reference assignment by Russian aphatic speakers with agrammatism. In 11th Symposium of Psycholinguistics: Book of Abstracts (Tenerife: University of La Laguna). $75-76$.

Reinhart, T. (2000). Strategies of anaphora resolution In Interface Strategies, eds. H. Bennis et al. (Amsterdam: Royal Academy of Artsand Sciences). 295-325.

Reuland, E. (2003). Anaphoric dependencies: A win- dow into the architecture of the language system. Glot international, 7(1/2), 3-25.

Reuland, E. J. (2011). Anaphora and language design. Cambridge, MA: MIT Press.

Rohde, H., \& Kehler, A. (2014). Grammatical and information-structural influences on pronoun production. Language, Cognition and Neuroscience, 29(8), 912-927. http://dx.doi.org/10.1080/ 01690965.2013 .854918

Sheldon, A. (1974). The role of parallel function in the acquisition of relative clauses in English. Journal of verbal learning and verbal behavior, 13(3), 272-281. http://dx.doi.org/10.1016/ S0022-5371(74)80064-2

Smyth, R. (1994). Grammatical determinants of ambiguous pronoun resolution. Journal of Psycholinguistic Research, 23(3), 197-229. doi:10.1007/ BF02139085

Stevenson, R. J., Nelson, A. W., \& Stenning, K. (1995). The role of parallelism in strategies of pronoun comprehension. Language and Speech, 38(4), 393-418. doi:10.1177/002383099503800404

Zuckerman, S, Vasic, N., Ruigendijk, E., and Avrutin, S. (2002-a). Experimental evidence for the Subject Rule. In Proceedings of IATL 18, eds. Y. Falk (The Israely Association for theoretical linguistics).

Zuckerman, S., Vasic, N., and Avrutin, S. (2002). The Syntax-Discourse Interface and the Interpretation of Pronominals by Dutch-Speaking Children. In BUCLD 26: Proceedings of the 26th annual conference on language acquisition and development, eds., S. F. B. Skarabela (Somerville: Cascadilla Press), 781-792. 